\title{
Design of vitrification solutions for the cryopreservation of embryos
}

\author{
J. Ali* and J. N. Shelton \\ Developmental Physiology Group, John Curtin School of Medical Research, Australian National \\ University, Canberra, Australia
}

\begin{abstract}
A series of experiments was performed to determine the concentrations at which ten cryoprotectants singly and in pairs would vitrify on plunging into liquid nitrogen and remain vitreous when warmed by plunging into a water bath at $25^{\circ} \mathrm{C}$. From these tests eight solutions (VS) were selected for testing of toxicity to mouse morulae in vitro. One of these (VS1) was modified as a further five VS of which one (VS11) was tested for toxicity to all stages of mouse embryos and to sheep compacted morulae. The concentrations at which the cryoprotectants vitrified on cooling were: butylene glycol, $3.0 \mathrm{~mol} \mathrm{l}^{-1}$; propylene glycol, $4.0 \mathrm{~mol} \mathrm{l}^{-1}$; dimethyl sulfoxide (DMSO) and glycerol $5.0 \mathrm{~mol} \mathrm{l}^{-1}$; ethylene glycol, $6.5 \mathrm{~mol} \mathrm{l}^{-1}$. None of these, at the highest concentration tested, remained vitreous during warming. Methanol and the high molecular weight polymers, dextran, Ficoll, polyethylene glycol and polyvinylpyrrolidone, did not vitrify at the concentrations tested. Toxicity studies showed the order of increasing toxicity to be ethylene glycol, methanol, DMSO, glycerol, propylene glycol and butylene glycol. Of the mixtures composed of two cryoprotectants, those containing ethylene glycol and glycerol were the least toxic at vitrifying concentrations. VS11 ( 6.0 mol ethylene glycol $\mathrm{l}^{-1}$ and $1.8 \mathrm{~mol}_{\text {glycerol }} \mathrm{l}^{-1}$ ) was well tolerated by mouse morulae, less well by eight- and one-cell embryos and poorly by two-cell embryos. Dilution of the VS11 from mouse embryos by exposure to $1.0 \mathrm{~mol}$ sucrose $1^{-1}$ for $10 \mathrm{~min}$ did not enhance their survival. VS14 (5.5 mol ethylene glycol $\mathrm{l}^{-1}$ and $1.0 \mathrm{~mol}$ sucrose $\mathrm{l}^{-1}$ ) was a good vitrifying mixture and was non-toxic to mouse embryos when they were exposed for up to $30 \mathrm{~min}$. The survival of sheep compacted morulae in vitro was not affected by exposure to VSII for up to $20 \mathrm{~min}$ when dilution of the VSII was done by exposure to $1.0 \mathrm{~mol}$ sucrose $1^{-1}$ for 10 min. Without sucrose dilution, exposure to VSI1 for 10 min was detrimental to embryo survival.
\end{abstract}

\section{Introduction}

Cryopreservation of embryos by vitrification requires a solution which is cryoprotectant, will vitrify on cooling at an easily achievable and repeatable rate, will remain vitreous on warming and is not toxic to embryos during the period of exposure before vitrification and during warming. Good vitrification may be obtained with high concentrations of a single cryoprotectant, but these concentrations are frequently toxic to embryos. Mixtures of cryoprotectants generally vitrify at lower concentrations (Fahy et al., 1987) and thus are likely to be less toxic to embryos.

The solute concentration at which vitrification occurs and the duration of exposure of embryos to pre-vitrification temperatures are inversely related to the rate of cooling. Thus for cryopreservation of embryos by vitrification, rapid cooling is indicated to minimize toxicity. The most rapid cooling rate that can be easily achieved without specialized equipment is that resulting from direct plunging into liquid nitrogen. For ease of application in the

*Present address: IVF Laboratory, Department of Obstetrics and Gynaecology, National University Hospital, Lower Kent Ridge Rd, Singapore 0511.

Received 21 December 1992. field or laboratory it is desirable that the vitrification medium remains vitreous during warming at room temperature.

The series of experiments described here was designed to determine the concentration at which cryoprotectants would vitrify when in solution singly or in combination, and to assess their toxicity to mouse and sheep embryos. In addition to the cryoprotectants commonly used for cryopreservation of embryos, several others were investigated. These included methanol, which is rapidly permeating and non-toxic to embryos and has been claimed to be an effective cryoprotectant (Rall et al., 1984; Czlonkowska et al., 1991); butylene glycol, found by Boutron (1990) to be a better glass former than other cryoprotectants, and high molecular weight polymers that reduce the vitrification concentration of solutions (Fahy et al., 1984). After the vitrification studies, selected cryoprotectants and combinations thereof were tested for toxicity to mouse and sheep embryos. Sucrose is frequently used during dilution of cryoprotectant from embryos to prevent excessive swelling which may occur when dilution is by direct exposure to physiological medium (Leibo and Mazur, 1978). In the experiments described here, the necessity to use sucrose for dilution of vitrifying cryoprotectant from embryos after warming was assessed. The eventual aim was Downloaded from Bioscientifica com at 04/26/2023 10:56:48 AN 
to develop a method for cryopreservation of embryos by vitrification.

\section{Materials and Methods}

\section{Vitrification studies}

The cryoprotectants investigated were: butylene glycol, dimethyl sulfoxide (DMSO), ethylene glycol, glycerol, methanol, propylene glycol, dextran (molecular weight 70000 ), Ficoll (molecular weight 70000), polyethylene glycol (molecular weight 80000 ) and polyvinylpyrrolidone (molecular weight $10000)$.

The solutions for testing were prepared in phosphatebuffered saline containing $5 \%(\mathrm{v} / \mathrm{v})$ fetal calf serum. The aim was to test all solutions up to a concentration of $6.0 \mathrm{~mol} \mathrm{l}^{-1}$ but butylene glycol was used only to $5.5 \mathrm{~mol} \mathrm{l}^{-1}$. The maximum concentration of Ficoll, dextran and polyvinylpyrrolidone was $20 \%(\mathrm{w} / \mathrm{v})$. Polyvinylpyrrolidone was tested at a maximum concentration of $10 \%(\mathrm{w} / \mathrm{v})$, as higher concentrations were known to be extremely toxic to embryos.

The tendency for solutions of two cryoprotectants in combination to vitrify was determined by examining a range of combinations at steps of $0.5 \mathrm{~mol}^{-1}(5 \%$ for the high molecular weight polymers) in a two-way matrix. For each pair of cryoprotectants tested there were usually 144 combinations.

Solutions were tested for vitrification in unsealed $0.25 \mathrm{ml}$ plastic insemination straws (I.M.V., L'aigle) filled at room temperature $\left(25^{\circ} \mathrm{C}\right)$ by suction with a syringe. The loaded straws were plunged directly into liquid nitrogen to test for vitrification on cooling. The ability of the solution to remain vitreous during warming was tested by plunging the vitrified straws into a water bath maintained at $25^{\circ} \mathrm{C}$. During cooling, vitrification was evidenced by the formation of a transparent glass; crystallization (ice formation) resulted in a milky appearance. During warming, solutions that did not devitrify were transformed from the solid clear state to the liquid state without evidence of a milky appearance. Devitrification (ice formation) conferred a milky appearance during warming.

\section{Toxicity studies}

The cryoprotectants tested for embryotoxicity were: butylene glycol, DMSO, ethylene glycol, glycerol, methanol and propylene glycol. As a result of these tests and the vitrification studies described above, 13 vitrification solutions (VS1-VS13) were formulated and tested for embryotoxicity. Cryoprotectant and VS solutions were made up in PBS containing $5 \%$ FCS.

\section{Recovery and culture of embryos}

Mouse embryos of all developmental stages were obtained from Swiss outbred mice without superovulation. The oestrous cycles of donor females were synchronized by pheromonal stimulation or Whitten effect (Whitten, 1957). Recovered embryos were pooled in small droplets of Hepes-buffered Whitten's medium (HWM) under paraffin oil and after discarding embryos of poor quality they were apportioned equally as appropriate for individual experiments. Mouse embryos were cultured in Whitten's medium (WM) (Whitten, 1971) up to the blastocyst or hatching blastocyst stage at $37^{\circ} \mathrm{C}$ in an atmosphere of $5 \% \mathrm{CO}_{2}$ in air.

Sheep morulae were recovered from superovulated Merino ewes (Hunter et al., 1955; Ryan et al., 1984) by flushing the uterine horns with Dulbecco's phosphate-buffered saline containing $5 \%$ fetal calf serum. Morphologically normal embryos were apportioned equally to treatments in the individual experiments. After exposure to the cryoprotectant under test, the sheep embryos were cultured in synthetic oviduct fluid (Tervit et al., 1972) for $48 \mathrm{~h}$.

\section{Experimental design}

Toxicity of cryoprotectants and VS to mouse morulae. Six cryoprotectants (butylene glycol, DMSO, ethylene glycol, glycerol, methanol and propylene glycol) and 13 combinations or vitrification solutions (VS) incorporating these compounds were tested. Eight of the VS (1-8) were selected from the results of vitrification tests and the others (VS9-VS13) were modifications of VS1 based on the results of early toxicity tests.

Each molarity of a cryoprotectant and each VS was tested separately for 5,10 and $20 \mathrm{~min}$ of embryo exposure at $25^{\circ} \mathrm{C}$ and a group of unexposed control embryos was included in each test. After exposure in small droplets under paraffin oil for the specified durations, the morulae were removed to $1 \mathrm{~mol}$ sucrose $\mathrm{I}^{-1}$ for $10 \mathrm{~min}$ at $25^{\circ} \mathrm{C}$ to dilute the cryoprotectant in the morulae. The morulae were then placed in HWM for 5 min at the same temperature and finally cultured in WM. The following day, the number of morulae that survived and proceeded to the blastocyst stage was recorded. There were three to six treatment replicates for each molarity of cryoprotectant and for each vitrification solution. As there was no significant heterogeneity attributable to replicates, they were pooled and the embryo survival rate for each time of exposure was compared with that for the control group by $\chi^{2}$ test. There was an average of 57 embryos in each pooled group in the testing of cryoprotectants and 63 in the testing of vitrification solutions.

Toxicity of VS11 to day-4 mouse embryos when diluted with or without sucrose at $25^{\circ} \mathrm{C}$. Day- 4 mouse morulae, early blastocysts and blastocysts were exposed to VS11 (for 3, 2 or $1 \mathrm{~min}$, respectively) which was diluted with 1 mol sucrose $\mathrm{I}^{-1}$ or directly with HWM. The embryos were then cultured in WM overnight and the survival of embryos was recorded.

Toxicity of VS11 to precompaction stages of mouse embryos. One-cell, two-cell and eight-cell embryos were exposed to VSII for 1, 5, 10 or $20 \mathrm{~min}$. VSII was diluted from the embryos by treatment with $1 \mathrm{~mol}$ sucrose $1^{-1}$ for $10 \mathrm{~min}$ followed by $5 \mathrm{~min}$ in HWM, or by directly diluting in medium. Treated and control embryos were cultured to the blastocyst stage in WM.

Toxicity of VS11 to sheep compacted morulae with and without sucrose dilution at $25^{\circ} \mathrm{C}$. Compacted sheep morulae were exposed to VS11 for 3, 5, 10, 15 or $20 \mathrm{~min}$. The VS was diluted 
Table 1. Concentrations $s^{\mathrm{a}}$ of cryoprotectants in combination that vitrified on plunging into liquid nitrogen and remained vitreous on warming to $25^{\circ} \mathrm{C}$

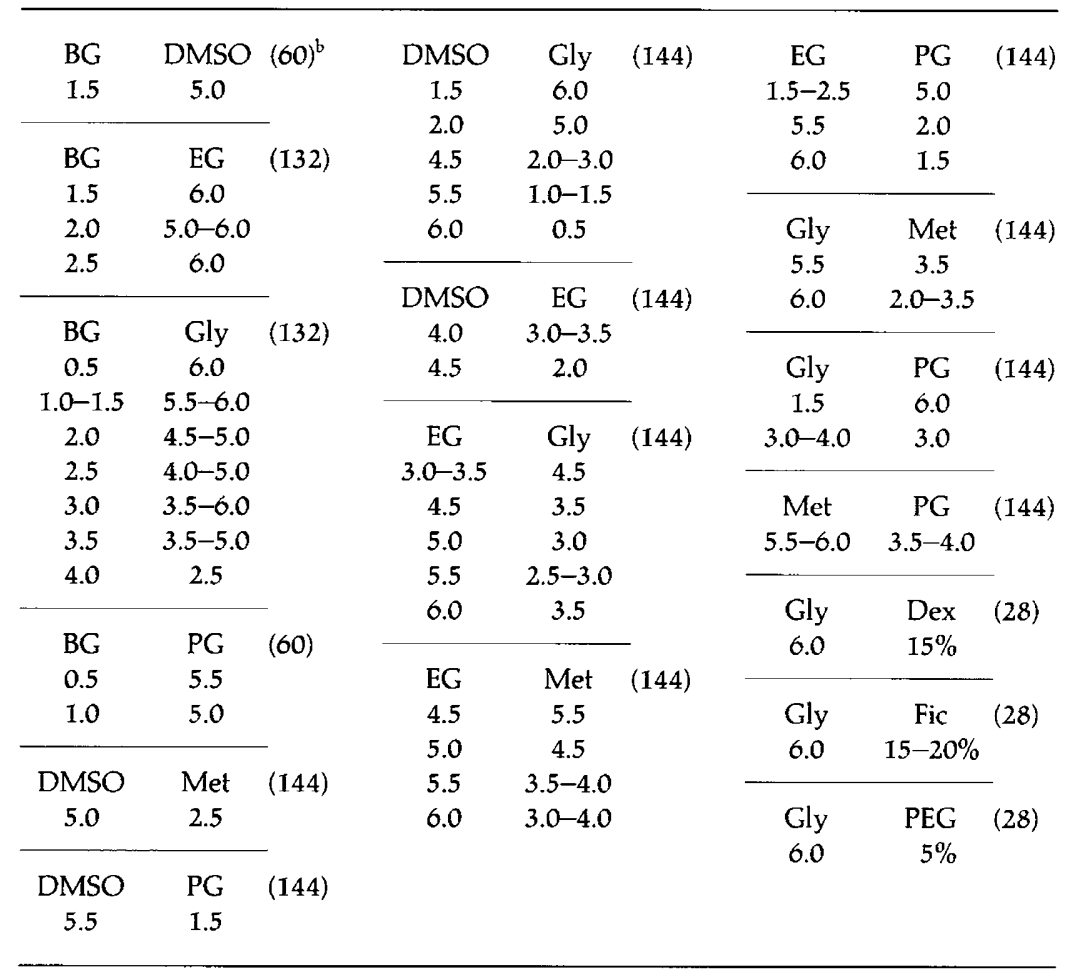

"Concentrations are in $\mathrm{mol} \mathrm{I}^{-1}$ except for dextran, Ficoll and polyethylene glycol. 'Numbers in parentheses are numbers of variants tested for each combination. BG: butylene glycol; EG: ethylene glycol; Gly: glycerol; PG: propylene glycol; DMSO: dimethyl sulfoxide; Met: methanol; Dex: dextran; Fic: Ficoll; PEG: polyethylene glycol.

with 1 mol sucrose $1^{-1}$ or directly in Hepes-buffered synthetic oviductal fluid medium. Treated embryos were cultured for 24-36 h in synthetic oviductal fluid (Tervit et al., 1972).

\section{Results}

\section{Vitrification studies}

Butylene glycol vitrified at $3.0 \mathrm{~mol}^{-1}$, propylene glycol at $4.0 \mathrm{~mol}^{-1}$, DMSO and glycerol at $5.0 \mathrm{~mol}^{-1}$. Ethylene glycol did not vitrify at $6.0 \mathrm{~mol}^{-1}$, but in a separate test was shown to vitrify at $6.5 \mathrm{~mol} \mathrm{l}^{-1}$. However, none of these remained completely vitreous during warming even at the maximum concentration tested. None of the high molecular weight polymers vitrified on their own at the concentrations tested and methanol did not vitrify at a concentration of $99.8 \%$.

When combinations of two cryoprotectants were tested, a number was found in each system that would vitrify on plunging into liquid nitrogen and remain vitreous on warming in a waterbath at $25^{\circ} \mathrm{C}$ (Table I). With many mixtures, when the concentration was increased beyond a certain point, the glass cracked during warming. (These concentrations are not included in Table 1.) It was found that no variants of the butylene glycol - methanol or the polyvinyl pyrrolidone - glycerol combinations satisfied the criteria of vitrification.

\section{Toxicity studies}

The survival rate of the control groups of embryos (one for each concentration of each cryoprotectant) ranged from $63 \%$ to $98 \%$. Ethylene glycol was the least toxic. Toxicity was not evident at $6.0 \mathrm{~mol} 1^{-1}$, the maximum concentration initially tested, but additional tests showed $7.0 \mathrm{~mol} \mathrm{l}^{-1}$ to be toxic after $5 \mathrm{~min}$. Ethylene glycol was followed in order of increasing toxicity by methanol, glycerol, DMSO, propylene glycol and butylene glycol. Toxicity was evident after exposure of morulae to $2.0 \mathrm{~mol}$ butylene glycol $\mathrm{I}^{-1}$ for $10 \mathrm{~min}$ (Table 2).

From the results of the vitrification experiments and the relative toxicity of individual cryoprotectants, eight (VS1-VS8) mixtures were selected for study of their toxicity to day- 4 mouse morulae. The composition of these mixtures and the duration of exposure at which toxicity was significant $(P<0.01)$ are shown (Table 3). VS1 was the least toxic mixture; VS5, of similar composition, was marginally toxic $(P<0.05)$ after $5 \mathrm{~min}$ (not shown in Table 4$)$. The remaining VS (9-13) were modifications of VS1 in which the aim was to reduce toxicity by decreasing the content of glycerol and increasing the content of ethylene glycol. Of these, VS11 and VS9 were the least toxic (Table 3) and VSII was selected for further tests.

Exposure of mouse blastocysts, early blastocysts and morulae to VS11 for 1, 2 and $3 \mathrm{~min}$, respectively, had no effect on subsequent development to hatching blastocysts, regardless of 
Table 2. The durations ${ }^{\mathrm{a}}$ of exposure to cryoprotectants that resulted in a significant $(P<0.01)$ decrease in survival of day -4 mouse morulae compared with control morulae

\begin{tabular}{|c|c|c|c|c|c|c|c|c|}
\hline \multirow[b]{3}{*}{ Cryoprotectant } & \multicolumn{8}{|c|}{ Duration of exposure (min) } \\
\hline & \multicolumn{8}{|c|}{ Concentration of cryoprotectant $\left(\mathrm{mol} \mathrm{l}^{-1}\right)$} \\
\hline & 1 & 2 & 3 & 4 & 5 & 6 & 7 & 8 \\
\hline Ethylene glycol & $>20$ & $>20$ & $>20$ & $>20$ & $>20$ & $>20$ & 5 & 5 \\
\hline Methanol & $>20$ & $>20$ & $>20$ & $>20$ & $>20$ & 10 & & \\
\hline Dimethyl sulfoxide & $>20$ & $>20$ & $>20$ & 20 & 5 & & & \\
\hline Glycerol & - & 20 & $>20$ & 10 & 10 & 5 & & \\
\hline Propylene glycol & $>20$ & $>20$ & $>20$ & 5 & & & & \\
\hline Butylene glycol & $>20$ & 10 & 5 & & & & & \\
\hline
\end{tabular}

'Embryos were exposed to each concentration of each cryoprotectant for 5, 10 and $20 \mathrm{~min}$.

Table 3. The composition of vitrification solutions (VS) and the durations of exposure that resulted in a significant $(P<0.01)$ decrease in survival of day- 4 morulae compared with control morulae

\begin{tabular}{|c|c|c|c|c|c|c|c|}
\hline \multirow[b]{2}{*}{ VS } & \multicolumn{6}{|c|}{ Concentration of component $\left(\mathrm{mol} \mathrm{I}{ }^{-1}\right)$} & \multirow{2}{*}{$\begin{array}{c}\text { Duration } \\
\text { of exposure } \\
\text { (min) }\end{array}$} \\
\hline & Gly & EG & Met & PG & DMSO & BG & \\
\hline 1 & 2.5 & 5.5 & & & & & 10 \\
\hline 2 & & 6.0 & 3.0 & & & & 5 \\
\hline 3 & & 6.0 & & 1.5 & & & 5 \\
\hline 4 & & 5.5 & & 2.0 & & & 5 \\
\hline 5 & 3.5 & 4.5 & & & & & 10 \\
\hline 6 & 3.0 & & & 3.0 & & & 5 \\
\hline 7 & & 3.0 & & & 4.0 & & 5 \\
\hline 8 & & 6.0 & & & & 1.0 & 5 \\
\hline 9 & 1.8 & 6.1 & & & & & 20 \\
\hline 10 & 1.5 & 6.5 & & & & & 10 \\
\hline 11 & 1.8 & 6.0 & & & & & 20 \\
\hline 12 & 1.5 & 6.3 & & & & & 5 \\
\hline I3 & & 8.0 & & & & & 5 \\
\hline
\end{tabular}

Gly: glycerol; EG: ethylene glycol; Met: methanol; PG: propylene glycol; DMSO: dimethyl sulfoxide; BG: butylene glycol.

whether dilution was done with or without sucrose. In control and treated groups of embryos group size varied from 47 to 67 and the survival rates were between $93 \%$ and $100 \%$.

Two-cell embryos did not tolerate even $1 \mathrm{~min}$ of exposure to VS1I and one-cell embryos were affected by exposure for $5 \mathrm{~min}$ (Table 4). Some two-cell embryos survived (nine of 64) when the VS11 was diluted with sucrose, whereas none (of 64) survived without sucrose. This suggests that two-cell mouse embryos may be more susceptible to osmotic shock than are other stages; experiments with more embryos would be necessary to verify this effect. There was some evidence that eight-cell embryos were affected by sucrose dilution after exposure to VSII for $5 \mathrm{~min}$, but this must be considered equivocal, because while the survival rate was different from that of the control embryos it was not different from that of eight-cell embryos from which the VSII was diluted without sucrose.

Exposure to VS11 for up to 20 min was not detrimental to sheep compacted morulae when the VSII was diluted with sucrose. Exposure for $10 \mathrm{~min}$ or longer was detrimental when followed by dilution without sucrose (Table 5).

\section{Discussion}

Experiments on vitrification demonstrated the considerable differences between cryoprotectants in the molarity at which they will vitrify. Thus butylene glycol vitrified at a concentration of $3 \mathrm{~mol}^{-1}$, whereas ethylene glycol did not vitrify at $6 \mathrm{~mol}^{-1}$. In a separate trial ethylene glycol vitrified at $6.5 \mathrm{~mol}$ $1^{-1}$. The vitrification concentrations of the other cryoprotectants were intermediate between these two extremes. Although the cryoprotectants vitrified on cooling, none of the cryoprotectants remained vitreous at the maximum concentration tested under the conditions of warming used here. It is probable that ice nuclei that formed during cooling did not have sufficient time to grow, but during warming they grew to result in the formation of macroscopic ice. It must be stressed that these conclusions on vitrification concentrations apply only to the conditions of these experiments, namely, $0.25 \mathrm{ml}$ of cryoprotectant in a Cassou straw cooled by plunging into liquid nitrogen and warmed by plunging into a waterbath at $25^{\circ} \mathrm{C}$. Volume and surface area affect the response of solutions to cooling and warming, and thus the concentration at which vitrification will occur at specified rates of temperature change. Slower cooling or warming rates result in crystallization. Nevertheless, the relative glass forming tendencies of the cryoprotectants tested were similar to those that apply at much slower cooling rates (Fahy et al., 1987). An interesting observation was that often a slight increase in solute concentration above the vitrification concentration would lead to cracking of the glass during cooling or warming. Cracking would be expected to damage cryopreserved biological material.

All of the cryoprotectants, with the exception of ethylene glycol, were toxic to day- 4 mouse morulae at less than maxi- 
Table 4. Development to blastocyst stage of one, two and eight-cell mouse embryos after exposure to VSII for $1,5,10$ or 20 min followed by dilution with or without sucrose

\begin{tabular}{|c|c|c|c|c|c|c|c|}
\hline \multirow{3}{*}{$\begin{array}{l}\text { Stage of } \\
\text { development }\end{array}$} & \multirow[b]{3}{*}{ Dilution } & \multicolumn{5}{|c|}{ Percentage of embryos that developed ( $n$ ) } & \multirow{3}{*}{$\begin{array}{l}\text { Number of } \\
\text { replicates }\end{array}$} \\
\hline & & \multirow[b]{2}{*}{ Control } & \multicolumn{4}{|c|}{ Duration of exposure (min) } & \\
\hline & & & 1 & 5 & 10 & 20 & \\
\hline \multirow[t]{5}{*}{ One-cell } & Without sucrose & & $\begin{array}{l}39.4 \\
(33)\end{array}$ & $\begin{array}{c}0 \\
(33)\end{array}$ & $\begin{array}{c}0 \\
(31)\end{array}$ & $\begin{array}{c}0 \\
(37)\end{array}$ & \multirow{5}{*}{2} \\
\hline & $P^{*}$ & & ns & & & & \\
\hline & & $\begin{array}{l}41.9 \\
(31)\end{array}$ & & & & & \\
\hline & With sucrose & & $\begin{array}{c}27.3 \\
(33)\end{array}$ & $\begin{array}{c}6.1 \\
(33)\end{array}$ & $\begin{array}{c}0 \\
(31)\end{array}$ & $\begin{array}{c}0 \\
(31)\end{array}$ & \\
\hline & $P^{*}$ & & ns & $<0.01$ & & & \\
\hline \multirow[t]{5}{*}{ Two-cell } & Without sucrose & & $\begin{array}{c}0 \\
(16)\end{array}$ & $\begin{array}{c}0 \\
(16)\end{array}$ & $\begin{array}{c}0 \\
(16)\end{array}$ & $\begin{array}{c}0 \\
(16)\end{array}$ & \multirow{5}{*}{1} \\
\hline & $P^{*}$ & & & & & & \\
\hline & & $\begin{array}{l}93.8 \\
(16)\end{array}$ & & & & & \\
\hline & With sucrose & & $\begin{array}{l}25.0 \\
(16)\end{array}$ & $\begin{array}{c}0 \\
(16)\end{array}$ & $\begin{array}{l}31.3 \\
(16)\end{array}$ & $\begin{array}{c}0 \\
(16)\end{array}$ & \\
\hline & $P^{*}$ & & $<0.001$ & & $<0.01$ & & \\
\hline \multirow[t]{5}{*}{ Eight-cell } & Without sucrose & & $\begin{array}{l}97.5 \\
(40)\end{array}$ & $\begin{array}{l}87.5 \\
(40)\end{array}$ & $\begin{array}{l}25.0 \\
(40)\end{array}$ & $\begin{array}{c}0 \\
(40)\end{array}$ & \multirow{5}{*}{5} \\
\hline & $P^{*}$ & & ns & ns & $<0.001$ & & \\
\hline & & $\begin{array}{l}100.0 \\
(40)\end{array}$ & & & & & \\
\hline & With sucrose & & $\begin{array}{l}100.0 \\
(35)\end{array}$ & $\begin{array}{l}77.1 \\
(35)\end{array}$ & $\begin{array}{l}71.4 \\
(35)\end{array}$ & $\begin{array}{l}27.3 \\
(44)\end{array}$ & \\
\hline & $P^{*}$ & & ns & $<0.05$ & $<0.01$ & $<0.001$ & \\
\hline
\end{tabular}

n: Number of embryos treated; ns: not significant; ${ }^{*}$ compared with controls.

Table 5. Development to blastocyst stage of sheep compacted morulae after exposure to VSI1 for $3,5,10,15$ or $20 \mathrm{~min}$ followed by dilution with or without sucrose

\begin{tabular}{|c|c|c|c|c|c|c|c|}
\hline \multirow{3}{*}{$\begin{array}{l}\text { Dilution } \\
\text { technique }\end{array}$} & \multicolumn{6}{|c|}{ Percentage embryos that developed $(n)$} & \multirow{3}{*}{$\begin{array}{c}\text { Number of } \\
\text { replicates }\end{array}$} \\
\hline & \multirow[b]{2}{*}{ Controls } & \multicolumn{5}{|c|}{ Duration of exposure (min) } & \\
\hline & & 3 & 5 & 10 & 15 & 20 & \\
\hline Without sucrose & $\begin{array}{l}84.6 \\
(13)\end{array}$ & $\begin{array}{l}100.0 \\
\text { (11) }\end{array}$ & $\begin{array}{l}87.5 \\
(8)\end{array}$ & $\begin{array}{l}18.2 \\
(11)\end{array}$ & $\begin{array}{l}25.0 \\
(8)\end{array}$ & $\begin{array}{c}0 \\
(10)\end{array}$ & 3 \\
\hline$p^{*}$ & & ns & ns & $<0.01$ & $<0.05$ & & \\
\hline With sucrose & $\begin{array}{l}61.5 \\
(13)\end{array}$ & $\begin{array}{l}81.8 \\
(11)\end{array}$ & $\begin{array}{l}60.0 \\
(5)\end{array}$ & $\begin{array}{l}81.8 \\
(11)\end{array}$ & $\begin{array}{l}60.0 \\
(5)\end{array}$ & $\begin{array}{l}40.0 \\
(10)\end{array}$ & 3 \\
\hline$P^{*}$ & & ns & ns & ns & ns & ns & \\
\hline
\end{tabular}

$n$ : Number of embryos treated; ns: not significant; ${ }^{*}$ compared with controls.

mum concentrations. Eight combinations of cryoprotectants were selected using the vitrification data and with emphasis on mixtures containing ethylene glycol because of its low toxicity.
The least toxic (VS1) was further modified and tests showed that

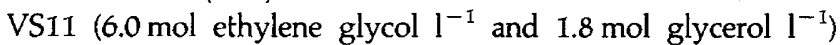
and VS9 (6.1 mol ethylene glycol $\mathrm{l}^{-1}$ and $1.8 \mathrm{~mol}_{\left.\text {glycerol } \mathrm{l}^{-1}\right)}$ ) Downloaded from Bioscientifica com at $04 / 26 / 2023$ 10:56:48AM 
were less toxic. VS13 represented an attempt to use only ethylene glycol as the vitrifying agent. At the concentration used it was toxic to mouse embryos. This demonstrates the advantage in using mixtures that combine the vitrifying properties of one cryoprotectant with the low toxicity of another.

Clearly ethylene glycol is the least toxic of the commonly used permeating cryoprotectants but, at the concentration necessary to achieve vitrification $\left(8.0 \mathrm{~mol} \mathrm{l}^{-1}\right)$ during cooling and warming, it is toxic. This indicated that a successful strategy might be to devise a mixture in which vitrification could be achieved at a non-toxic level of permeating cryoprotectant by the addition of a non-permeating cryoprotectant. Subsequent to the experiments described here, a mixture of $5.5 \mathrm{~mol}$ ethylene glycol $1^{-1}$ and $1.0 \mathrm{~mol}$ sucrose $1^{-1}$ was tested. Although neither component will vitrify on its own, the combination, within a $0.25 \mathrm{ml}$ straw, will vitrify on plunging into liquid nitrogen and remains vitreous on warming in a waterbath at $25^{\circ} \mathrm{C}$. Furthermore the subsequent rate of development of mouse morulae was completely normal after exposure to this mixture for $30 \mathrm{~min}$. This mixture was designated VS14 and its use for successful vitrification of mouse and sheep embryos will be described in subsequent papers. It is interesting that after an exhaustive programme of testing of cryoprotectants for capacity to vitrify and for embryotoxicity, we arrived at a mixture similar to that of Kasai et al. (1990) who added Ficoll and sucrose to obtain vitrification at a non-toxic level of ethylene glycol.

Embryotoxicity may be osmotic or biochemical in origin and both forms of toxicity are affected by the concentration of the cryoprotectant and its rate of permeation. A greal deal of the published data on toxicity of cryoprotectants has been generated from experiments in which the system was cooled slowly and involved the use of tissue slices (e.g. Fahy et al., 1987). Toxicity of the mixtures used here was not correlated with the total molarity of the mixture but rather with the chemical components. Thus, all the mixtures that included propylene glycol were toxic to mouse morulae after $5 \mathrm{~min}$, despite having lower molarities than less toxic mixtures. This finding suggests that the toxicity is at least partly biochemical. Propylene glycol is a good vitrifying agent but its toxicity does not favour its use in vitrification of embryos. Nevertheless it has been used successfully for this purpose (e.g. Rall and Fahy, 1985; Scheffen et al., 1986; Rall, 1987; Massip et al., 1989). Data on permeation of sheep embryos (Szell et al., 1989) show that ethylene glycol permeates more rapidly than does propylene glycol which permeates more rapidly than does glycerol. This order is unrelated to the order of embryotoxicity observed and is further evidence of a significant biochemical component in the embryotoxicity of cryoprotectants.

Butylene glycol is a very good vitrifying agent, but in experiments described here it was very toxic to mouse morulae. The butylene glycol used was a racemic mixture of dextro-, laevo- and meso-isomers of which the individual constituents were not known. In view of the superior vitrifying characteristics of butylene glycol, its isomers should be separately tested for embryotoxicity. It is interesting that the mixture VS2 which contained 3.0 mol methanol $1^{-1}$ and 6.0 mol ethylene glycol $1^{-1}$ was toxic despite the finding that neither constituent was toxic alone. This may be an example of osmotic toxicity due to the high molarity of the mixture.
Other workers have overcome the toxic effects of cryoprotectants by decreasing the temperature during embryo exposure (Rall and Fahy, 1985; Rall, 1987; Ishimori et al., 1992; Isachenko et al., 1992; Cseh et al., 1992). The present investigation aimed at obviating the need to reduce the temperature of exposure because such a procedure would require cooling apparatus for the precise control of temperature.

Use of sucrose to ameliorate osmotic shock was not necessary during dilution of VS11 from day-4 mouse embryos after the durations of exposure used here. This was because these durations of exposure were too short to allow establishment of high intracellular concentrations of VS11. Furthermore, the high permeativity of ethylene glycol reduces its potential to cause osmotic shock. However, there was clear evidence that sucrose dilution was beneficial to survival of sheep embryos after exposure to VSI1 for $10 \mathrm{~min}$ or longer.

The data presented here constitute a systematic examination of the commonly used cryoprotectants for the purpose of devising a vitrification solution suited to the cryopreservation of embryos. Massip et al. (1989) used a similar approach but examined only two cryoprotectants and Kasai et al. (1990) compared three permeating cryoprotectants. Other investigators have used a less systematic approach to the design of a vitrification solution.

VS11 and VS14 have been used in vitrification of mouse and sheep embryos with extremely encouraging results in terms of in vitro and in vivo survival. These data will be reported elsewhere.

\section{References}

Boutron P (1990) Levo- and dextro-2,3-butanediol and their racemic mixture very efficient solutes for vitrification Cryobiology 27 55-59

Cseh S, Horlacher W, Brem G, Seregi J and Solti L (1992) Vitrification of mouse embryos in two cryoprotectant solutions Theriogenology $37 \quad 198$ (Abstract)

Czlonkowska M, Papis K, Guszkiewicz A, Kossakowski $\mathbf{M}$ and Eysymont $\mathbf{U}$ (1991) Freezing of sheep embryos in $3.0 \mathrm{M}$ methanol Cryo-letters 12 11-16

Fahy GM, MacFarlane DR, Angell CA and Meryman HT (1984) Vitrification as an approach to cryopreservation Cryobiology $21407-426$

Fahy GM, Levy DI and Ali S (1987) Some emerging principles underlying the physical properties, biological actions, and utility of vitrification solutions Cryobiology 24 196-213

Hunter GL, Adams CE and Rowson LEA (1955) Interbreed ovum transfer in sheep Journal of Agricultural Science 46 143-149

Isachenko VV, Ostashko FI and Isachenko EF (1992) Vitrification and ultra-rapid freezing of rat embryos Theriogenology 37227 (Abstract)

Ishimori H, Takahashi $\mathbf{Y}$ and Kanagawa $\mathbf{H}$ (1992) Viability of vitrified mouse embryos using various cryoprotectant mixtures Theriogenology 37 481-487

Kasai M, Komi JH, Takakamo A, Tsudera H, Sakurai T and Machida T (1990) A simple method for mouse embryo cryopreservation in a low toxicity vitrification solution, without appreciable loss of viability Joumal of Reproduction and Fertility 89 91-97

Leibo SP and Mazur P (1978) Methods for the preservation of mammalian embryos by freezing. In Methods in Mammalian Reproduction pp 179-201 Ed. JC Daniel, Jr. Academic Press, New York

Massip A, Van der Zwalmen P, Scheffen B and Ectors F (1989) Some significant steps in the cryopreservation of mammalian embryos with a note on a vitrification procedure Animal Reproduction Science 19 117-129

Rall WF (1987) Factors affecting the survival of mouse embryos cryopreserved by vitrification Cryobiology 24 387-402

Rall WF and Fahy GM (1985) Vitrification: a new approach to embryo cryopreservation Theriogenology 23220 (Abstract) Downloaded from Bioscientifica.com at 04/26/2023 10:56:48AM 
Rall WF, Czlonkowska M, Barton SC and Polge C (1984) Cryoprotection of day-4 mouse embryos by methanol Journal of Reproduction and Fertility 70 293-300

Ryan JP, Bilton RJ, Hunton JR and Maxwell WMC (1984) Superovulation with a combination of PMSG and FSH-P. In Reproduction in Sheep pp 338-341 Eds DR Lindsay and DT Pearce. Australian Academy of Science, Canberra

Scheffen B, Van der Zwalmen P and Massip A (1986) A simple and efficient procedure for preservation of mouse embryos by vitrification Cryo-Letters 7 $260-269$
Szell A, Shelton JN and Szell K (1989) Osmotic characteristics of sheep and cattle embryos Cryobiology 26 297-301

Tervit HR, Whittingham DG and Rowson LEA (1972) Successful culture in vitro of sheep and cattle ova Joumal of Reproduction and Fertility 30 493-497

Whitten WK (1957) Effect of exteroreceptive factors on the oestrous cycle of mice Nature 1801436

Whitten WK (1971) Nutrient requirements for the culture of preimplantation embryos in vitro Advances in Bioscience 6 129-141 